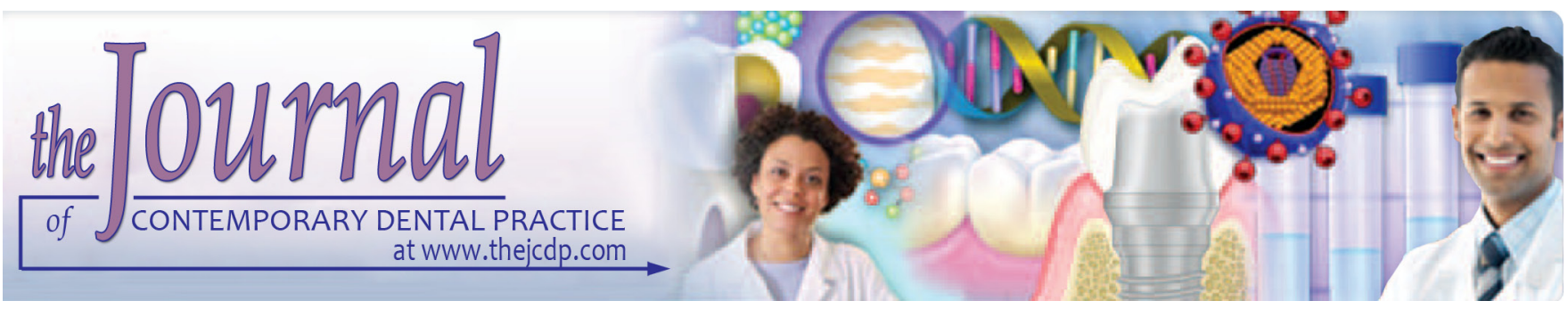

\title{
Effects of Diode Laser Debonding of Ceramic Brackets on Enamel Surface and Pulpal Temperature
}

\author{
${ }^{1}$ Soghra Yassaei, ${ }^{2}$ Azadeh Soleimanian, ${ }^{3}$ Zahra Ebrahimi Nik
}

\begin{abstract}
Aim: Debonding of ceramic brackets due to their high bond strength and low fracture toughness is one of the most challenging complications of orthodontic clinicians. Application of lasers might be effective in the debonding of ceramic brackets as they reduce bond strength of resins and, therefore, can eliminate the risk of enamel damage. However, the thermal effects of laser radiation on dental tissue can cause undesirable results. The aim of this study is to evaluate the enamel surface characteristics and pulpal temperature changes of teeth after debonding of ceramic brackets with or without laser light.
\end{abstract}

Materials and methods: Thirty polycrystalline brackets were bonded to 30 intact extracted premolars, and later debonded conventionally or through a diode laser $(2.5 \mathrm{~W}, 980 \mathrm{~nm})$. The laser was applied for 10 seconds with sweeping movement. After debonding, the adhesive remnant index (ARI), the lengths and frequency of enamel cracks were compared among the groups. The increase in intrapulpal temperature was also measured. The collected data were analyzed by Chi-squared test and paired t-test using Statistical Package for Social Sciences (SPSS) software.

Results: There was no case of enamel fracture in none of the groups. Laser debonding caused a significant decrease in the frequency and lengths of enamel cracks, compared to conventional debonding. In laser debonding group, the increase in intrapulpal temperature $\left(1.46^{\circ} \mathrm{C}\right)$ was significantly below the benchmark of $5.5^{\circ} \mathrm{C}$ for all the specimens. No significant difference was observed in ARI scores among the groups.

Conclusion: Laser-assisted debonding of ceramic brackets could reduce the risk of enamel damage, without causing thermal damage to the pulp. However, some increases in the length and frequency of enamel cracks should be expected with all debonding methods.

${ }^{1-3}$ Department of Orthodontics, Shahid Sadoughi University of Medical Sciences Yazd, Iran

Corresponding Author: Zahra Ebrahimi Nik, Postgraduate Student, Department of Orthodontics, Shahid Sadoughi University of Medical Sciences Yazd, Iran, Phone: 989159968117 e-mail: z_3nik@yahoo.com
Keywords: Ceramic bracket, Diode laser, Debonding, Enamel damage, Pulpal temperature, Laboratory research.

How to cite this article: Yassaei S, Soleimanian A, Nik ZE. Effects of Diode Laser Debonding of Ceramic Brackets on Enamel Surface and Pulpal Temperature. J Contemp Dent Pract 2015;16(4):270-274.

\section{Source of support: Nil}

Conflict of interest: None

\section{INTRODUCTION}

Ceramic orthodontic brackets were introduced in the mid 1980s. The superior esthetics they offer compared with their metal counterparts make them the preferred brackets for many patients. ${ }^{1,2}$ Most ceramic brackets are made from alumina in either polycrystalline or monocrystalline form depending on their method of fabrication. Ceramic brackets provide higher strength, more resistance to deformation and better color stability. ${ }^{2-4}$ However, they have significantly lower fracture toughness and are more likely to shatter during debonding. ${ }^{3}$ Also, the high bracket bond strength could cause enamel damage at debonding. ${ }^{1,3,5}$ Enamel damage including enamel cracks or enamel fractures can lead to poor esthetics or even costly restorative treatments. On the other hand, bracket fracture which occurs in 10 to $30 \%$ of conventional removal procedures ${ }^{6}$ could cause eye injury or aspiration of bracket fragments. To avoid these, several debonding techniques have been suggested, such as ultrasonic debonding, electrothermal debonding, and the use of specially designed instruments for mechanical debonding. ${ }^{1,2}$ In addition, lasers with different wavelength have been used experimentally to debond ceramic brackets since the 1990s. ${ }^{4}$ Clinical application of laser debonding, if practical, would make less patient discomfort compared to conventional methods. ${ }^{5}$

Strobl et $\mathrm{al}^{7}$ investigated the effects of $\mathrm{CO}_{2}$ and Nd:YAG lasers on ceramic brackets debonding. They 


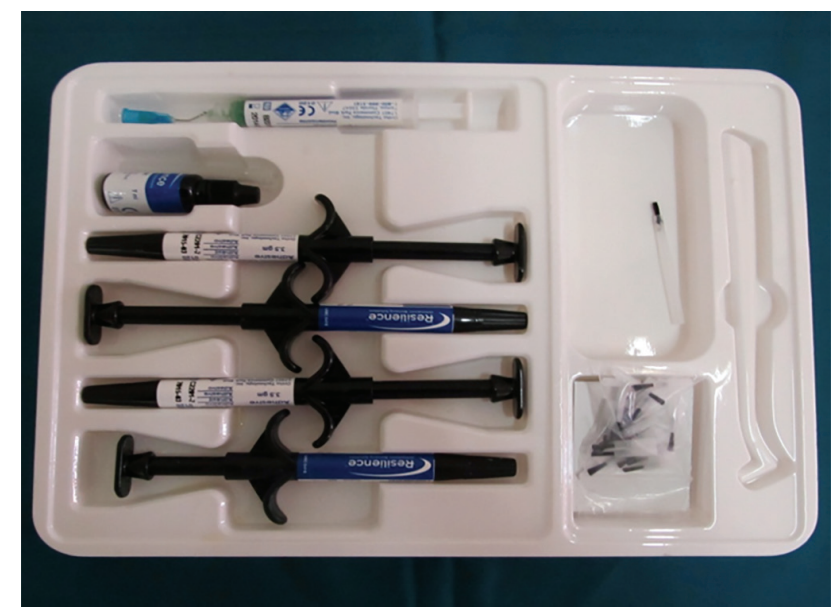

Fig. 1: Bonding system (Resilience, Ortho technology, Tampa, Florida, USA)

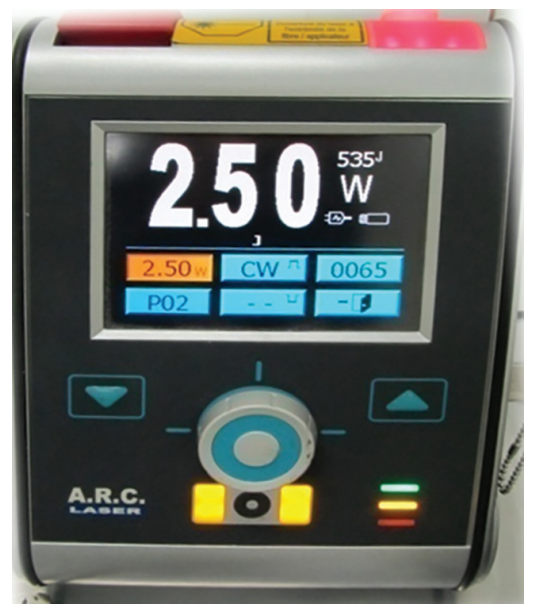

Fig. 3: Diode laser (Fox, ARC, Germany). For lasing the samples of this study, a wavelength of $980 \mathrm{~nm}$ and output of $2.5 \mathrm{~W}$ was used

found that the use of lasers dramatically decreased the required force for debonding, resulted in lowering the risk of enamel damage and bracket fracture.

Several studies reported that bracket removal with Er:YAG laser was effective and the risk of enamel or pulpal damage was lowered. ${ }^{8,9}$

While different studies have been investigated the effects of various lasers on bond strength of ceramic brackets, only a few well designed ones exist which evaluate the effects of lasers on enamel or pulpal damage., $3,7-10$

The aim of this study was to evaluate the enamel surface characteristics, adhesive remnant index and the intrapulpal temperature after application of diode laser for ceramic bracket debonding.

\section{MATERIALS AND METHODS}

In this parallel lab trial study, 30 noncarious human premolars mounted in acrylic resin were used.

To assess the enamel cracks before bracket bonding, the buccal surface of teeth were cleaned and photographed using digital camera of stereomicroscope (Olympus, SZX16, Japan) with 23.5 times magnification.

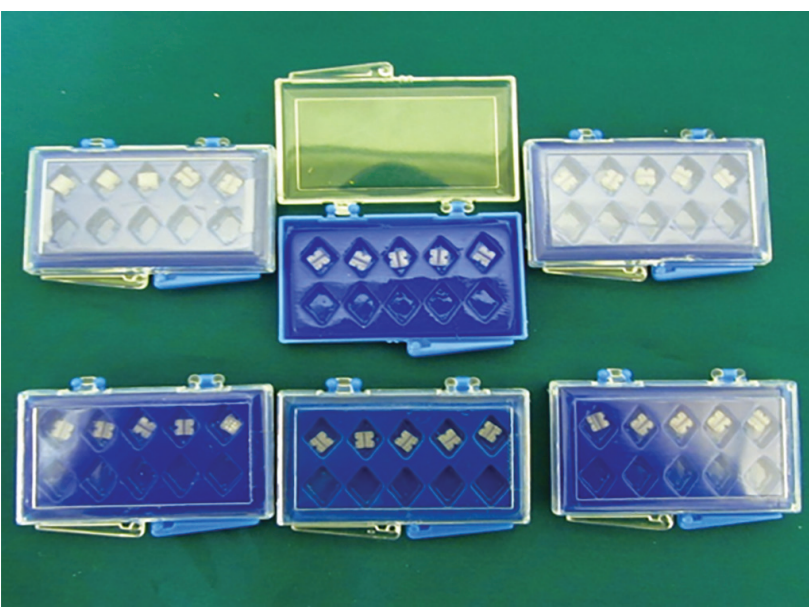

Fig. 2: Polycrystalline ceramic brackets (Allure US Patent $4,936,773$ ). Thirty premolar brackets were used in this study

The surface of enamel to be bonded were etched with a $37 \%$ phosphoric acid gel for 30 seconds, rinsed with water for 20 seconds, and completely dried with air spray. A thin layer of bonding primer (Resilience, Ortho Technology, Tampa, Florida, USA) was applied and the polycrystalline ceramic brackets (Allure US Patent $4,936,773$ ) were bonded to the buccal surfaces of teeth (Figs 1 and 2). All samples were light-cured for 20 seconds. After the bonding procedures, the teeth were stored in water at $37^{\circ} \mathrm{C}$ for more than 24 hours to ensure complete polymerization.

Specimens were randomly divided into two groups of 15 teeth. In the first group, brackets were debonded using debonding pliers according to the manufacturers' instruction.

In the second group, diode laser (Fox, ARC, Germany) with a wavelength of $980 \mathrm{~nm}$ and output of $2.5 \mathrm{~W}$ (Fig. 3) was applied to anterior surface of brackets for 10 seconds (5 seconds from mesial and 5 seconds from distal direction). The tip of laser probe was held at $5 \mathrm{~mm}$ distance to the bracket surfaces and it was moved with sweeping motion parallel to the bracket slot. Three seconds after the diode laser was applied, the brackets were removed using the same manufacturer's instruments as used in the first group.

After bracket removal, each enamel surface was evaluated under a stereoscopic magnifying at $10 \times$ magnification and characterized according to ARI scores established by Artun and Bergland, as follows: 0: no composite remaining on the tooth; 1 : less than half of the composite remaining on the tooth; 2: more than half of the composite remaining on the tooth; 3 : all composite remaining on the tooth.

To measure the intrapulpal temperature of laserassisted debonding teeth, an access cavity on the lingual surface was prepared by a long fissure bur. A K-type thermocouple was positioned in the cavity to contact its 

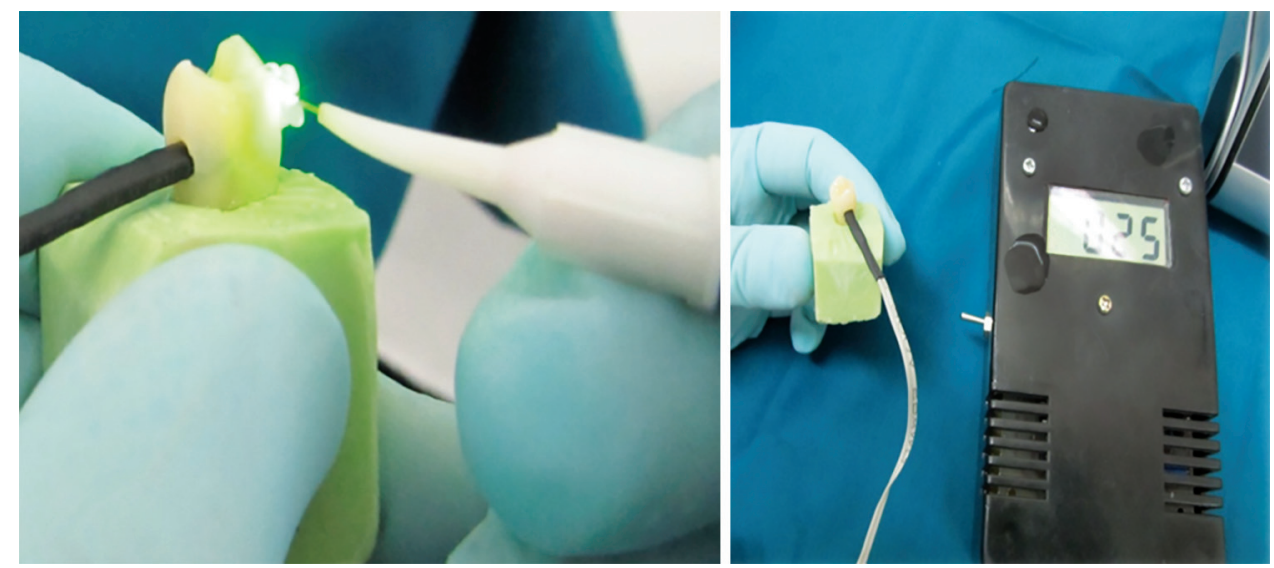

Fig. 4: Intrapulpal temperature recording. A K-type thermocouple system was positioned in prepared lingual cavity in order to record the intrapulpal temperature while lasing the ceramic brackets from buccal surface
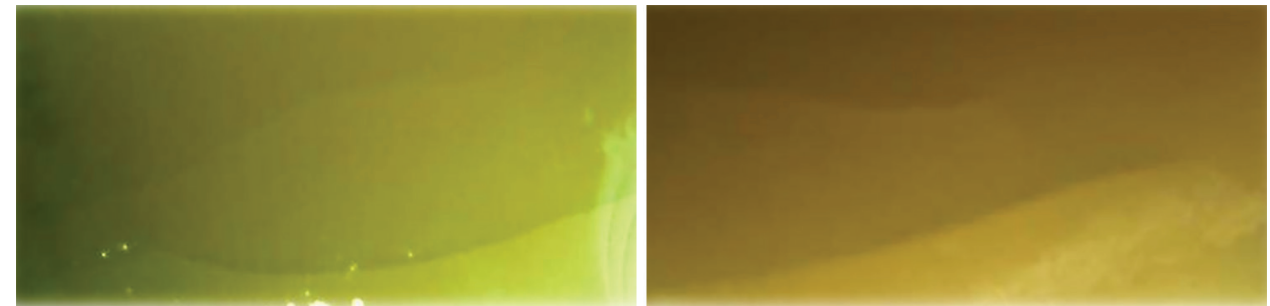

Fig. 5: Enamel cracks observed under stereomicroscope

sensor with the buccal wall of the cavity just below the bracket. While lasing, the changes in intrapulpal temperature were recorded (Fig. 4) and compared with the standard threshold which is $5.5^{\circ} \mathrm{C}$

Finally, the remnant adhesive on enamel surfaces were completely removed by tungsten carbide bur and all samples were photographed for the second time under the exact same conditions of the first photography.

The data were entered into a computer using the Statistical Package for Social Sciences (SPSS 15.5) software and analyzed by 'Chi-square' test and 'paired t-test' and statistical significance was considered to be $\mathrm{p}$-value $\leq 0.05$.

\section{RESULTS}

No enamel fracture or bracket failure was observed during debonding of brackets in none of the groups.

There were no significant between group differences in the number and lengths of enamel cracks (Fig. 5) before bracket bonding. However, there was a significant increase in the number and lengths of enamel cracks in all samples after the brackets had been removed. The mean length and frequency values, SDs of enamel cracks, and the difference before bonding and after removal of ceramic brackets are given in Tables 1 and 2 .

The t-test showed that samples debonded without laser had significantly more enamel cracks, also the length of cracks were significantly longer in this group compared with the laser-aided debonding samples, p-value; 0.045 and 0.005 respectively.

When the laser was not applied, $53.3 \%$ of the debonded brackets had an ARI score of 2 . With laser-aided debonding, the highest frequency of the ARI score was of one in $46.7 \%$ of samples. However, Chi-square test showed that the differences were not statistically significant $(\mathrm{p}=$ 0.624). Table 3 presents ARI data for the groups.

An increase in intrapulpal temperature of $1.46 \pm 0.64^{\circ} \mathrm{C}$ was noticed in the laser debonded samples. This increase was significantly below the temperature threshold $\left(5.5^{\circ} \mathrm{C}\right)$ required to cause pulpal damage. Table 4 shows the intrapulpal temperature before and after diode laser debonding.

\section{DISCUSSION}

With increase in the number of adults seeking orthodontic treatment, esthetic is becoming the primary concern of patients. ${ }^{11}$ While the metal brackets are the most common brackets used in orthodontics, they are more visible and less comfortable for patients. However, ceramic brackets offer better esthetics, higher strength and more resistance to deformation. ${ }^{2-4}$ A big challenge in the course of orthodontic treatment is debonding of brackets without causing enamel or bracket damages. Several debonding techniques have been suggested, such as ultrasonic debonding, electrothermal debonding, ${ }^{12}$ and the use of specially designed instruments for mec- 
Effects of Diode Laser Debonding of Ceramic Brackets on Enamel Surface and Pulpal Temperature

Table 1: Frequency of enamel cracks before bonding and after debonding

\begin{tabular}{lllll}
\hline & & \multicolumn{2}{c}{$\begin{array}{c}\text { Number of enamel } \\
\text { cracks }\end{array}$} & $\begin{array}{l}\text { Paired } \\
\text { t-test }\end{array}$ \\
\cline { 2 - 5 } & & $\begin{array}{l}\text { Before } \\
\text { bonding }\end{array}$ & $\begin{array}{l}\text { After } \\
\text { debonding }\end{array}$ & p-value \\
\hline Groups & Mean & $3 / 46$ & $5 / 26$ & $<0 / 001$ \\
\hline $\begin{array}{l}\text { Group 1 } \\
\text { conventional } \\
\text { debonding) }\end{array}$ & SD & $1 / 72$ & $1 / 86$ & \\
$\begin{array}{l}\text { Group 2 (laser } \\
\text { debonding) }\end{array}$ & Mean & $3 / 33$ & $4 / 33$ & $0 / 001$ \\
\hline
\end{tabular}

SD: Standard deviation
Table 2: The lengths of enamel cracks before bonding and after debonding

\begin{tabular}{lllll}
\hline & & \multicolumn{2}{c}{$\begin{array}{c}\text { Lengths of enamel } \\
\text { cracks }\end{array}$} & $\begin{array}{l}\text { Paired } \\
\text { t-test }\end{array}$ \\
\cline { 2 - 4 } Groups & Mefore & $\begin{array}{l}\text { After } \\
\text { debonding }\end{array}$ & p-value \\
\hline $\begin{array}{l}\text { Group 1 } \\
\text { (conventional } \\
\text { debonding) }\end{array}$ & SD & $9 / 18$ & $12 / 96$ & $<0 / 001$ \\
$\begin{array}{l}\text { Group 2 (laser } \\
\text { debonding) }\end{array}$ & Mean & $9 / 85$ & $5 / 67$ & \\
\hline
\end{tabular}

SD: Standard deviation

Table 3: Quantities and values attributed to each group according to the ARI

\begin{tabular}{|c|c|c|c|c|c|}
\hline \multirow[b]{2}{*}{ Groups } & \multicolumn{4}{|c|}{ ARI score } & \multirow[b]{2}{*}{$p$-value } \\
\hline & 0 & 1 & 2 & 3 & \\
\hline Conventional debonding & $1(6.7 \%)$ & $3(20 \%)$ & $8(53.3 \%)$ & $3(20 \%)$ & $0 / 624$ \\
\hline Laser debonding & $1(6.7 \%)$ & $7(46.7 \%)$ & $5(33.3 \%)$ & $2(13.3 \%)$ & \\
\hline
\end{tabular}

ARI: Adhesive remnant index

Table 4: Changes in intrapulpal temperature

\begin{tabular}{lll}
\hline & Before debonding & After debonding \\
\cline { 2 - 3 } Intrapulpal temp. & $26.47^{\circ} \mathrm{C}$ & $27.93^{\circ} \mathrm{C}$ \\
\hline & Changes in temp:1.46 & $\mathrm{p}<0 / 001$ \\
\hline
\end{tabular}

hanical debonding. ${ }^{1,2}$ In addition, lasers with different wave- length have been used experimentally to debond ceramic brackets since the 1990s. In the present study, the effects of the laser-aided debonding of ceramic brackets were investigated with the use of $810 \mathrm{~nm}$ diode laser. The small size and low cost of diode lasers made them favorable for use in orthodontic practice. ${ }^{1}$

In this study, significant differences were found between study groups in terms of the number and lengths of enamel cracks which are similar to the results of previous studies. Zachrisson et $\mathrm{al}^{13}$ reported remarkably less enamel cracks in control teeth compared to teeth under orthodontic treatment. Kitahara-Ceia et $\mathrm{al}^{14}$ and Eliades et $\mathrm{al}^{15}$ evaluated the bonding of ceramic brackets and also observed more damage associated with the removal of chemically bonded brackets.

Adhesive remnant index is an important criterion for evaluation of the enamel damage risk caused by debonding. ${ }^{3}$ Bonding failure could happen in enamel-adhesive interface, bracket-adhesive interface or in adhesive which each of these patterns has its own advantages and disadvantages. For instance, bond failure in bracket-adhesive interface decreases the risk of enamel damage, however, it is a time consuming procedure to remove the entire remnant adhesive from the enamel surface. ${ }^{16}$ In this project, there were found no statistical differences between the study groups regarding the location of bond failure which mainly were in bracket-adhesive interface or cohesive failure. When brackets were conventionally removed
$73 \%$, and were debonded by laser $80 \%$ of brackets showed an ARI of 1 and 2 which means 1 to $99 \%$ of adhesive had been remained on enamel surface. Similarly, Romano et $\mathrm{al}^{17}$ reported that the most bond failure occurred in adhesive-bracket interface when using Transbond XT composite, however, when using Z-100 or Concise composite more bond failure was noticed in bracket-enamel interface. Fernandez and Canut ${ }^{18}$ also showed that bond failure occurred mainly between bracket and adhesive. Different types of brackets and composites and different methods of applying debonding force probably influence the location of bond failure.

A thermocouple system has been used in this study to investigate the change in temperature during the diode laser debonding procedure. Zach and Cohen, ${ }^{19}$ using monkey teeth, showed that a rise of $5.5^{\circ} \mathrm{C}$ in the pulp caused considerable damage, resulting in complete loss of vitality in $15 \%$ of the teeth. Serebro et $\mathrm{al}^{20}$ Goodis et $\mathrm{l}^{21}$ also considered intrapulpal temperature increase of $5.5^{\circ} \mathrm{C}$ acceptable. Results of this study indicated that while lasing, the increase in the intrapulpal temperature was significantly lower than the temperature at which the tooth pulp is necrotized $(5.5 \mathrm{uC})$. The sweeping motion, applied in this study during lasing, probably had an important role in controlling the intrapulpal temperature because it distributed the heat on to the entire surface of the teeth. These results agree with those of previous reports. Obata et al reported that irradiating the ceramic brackets with super plus $\mathrm{CO}_{2}$, during debonding showed a $1.4^{\circ} \mathrm{C}$ temperature increase in the dental pulp at $2 \mathrm{~W}$ and an increase of $2 \cdot 1^{\circ} \mathrm{C}$ at $3 \mathrm{~W}$. These temperature increases were within the physiologically acceptable limits of the pulp. ${ }^{22}$ 


\section{CONCLUSION}

Based on the results of this study, we can conclude that the laser-assisted debonding is capable of lowering the risk of enamel damage during the debonding procedure. There was no difference in the ARI score between the two brackets. It also has no pulpal side effects. Therefore, laser debonding could facilitate developing smaller, more esthetic brackets without incurring a higher incidence of spontaneous debonding during orthodontic treatment.

\section{REFERENCES}

1. Feldon PJ, Murray PE, Burch JG, Meister M, Freedman MA. Diode laser debonding of ceramic brackets. Am J Orthod Dentofac Orthop 2010;138(4):458-462.

2. Ahrari F, Heravi F, Fekrazad R, Farzanegan F, Nakhaei S. Does ultra-pulse $\mathrm{CO}_{2}$ laser reduce the risk of enamel damage during debonding of ceramic brackets? Lasers Med Sci 2012;27(3):567-574.

3. Tehranchi A, Fekrazad R, Zafar M, Eslami B, Kalhori $\mathrm{KA}$, Gutknecht N. Evaluation of the effects of $\mathrm{CO}_{2}$ laser on debonding of orthodontics porcelain brackets vs the conventional method. Lasers Med Sci 2011;26(5):563-567.

4. Sarp AS, Gulsoy M. Ceramic bracket debonding with ytterbium fiber laser. Lasers Med Sci 2011;26(5):577-584.

5. Hayakawa K. Nd:YAG laser for debonding ceramic orthodontic brackets. Am J Orthod Dentofac Orthop 2005;128(5): 638-647.

6. Azzeh E, Feldon PJ. Laser debonding of ceramic brackets: a comprehensive review. Am J Orthod Dentofac Orthop 2003; 123(1):79-83.

7. Strobl K, Bahns TL, Willham L, Bishara SE, Stwalley WC. Laser-aided debonding of orthodontic ceramic brackets. Am J Orthod Dentofac Orthop 1992;101(2):152-158.

8. Oztoprak MO, Nalbantgil D, Erdem AS, Tozlu M, Arun T. Debonding of ceramic brackets by a new scanning laser method. Am J Orthod Dentofac Orthop 2010;138(2):195-200.

9. Nalbantgil D, Oztoprak MO, Tozlu M, Arun T. Effects of different application durations of ER:YAG laser on intrapulpal temperature change during debonding. Lasers Med Sci 2011; 26(6):735-740

10. Iijima M, Yasuda Y, Muguruma T, Mizoguchi I. Effects of $\mathrm{CO}_{2}$ laser debonding of a ceramic bracket on the mechanical properties of enamel. Angle Orthod 2010;80(6):1029-1035.

11. Winchester LJ. Bond strengths of five different ceramic brackets: an in vitro study. Eur J Orthod 1991;13(4):293-305.

12. Bishara SE, Trulove TS. Comparisons of different debonding techniques for ceramic brackets: an in vitro study. Part Ibackground and methods. Am J Orthod Dentofac Orthop 1990;98(2):145-153.

13. Zachrisson BU, Skogan O, Hoymyhr S. Enamel cracks in debonded, debanded, and orthodontically untreated teeth. Am J Orthod 1980;77(3):307-319.

14. Kitahara-Ceia FM, Mucha JN, Marques dos Santos PA. Assessment of enamel damage after removal of ceramic brackets. Am J Orthod Dentofac Orthop 2008;134(4):548-555.

15. Eliades T, Viazis AD, Lekka M. Failure mode analysis of ceramic brackets bonded to enamel. Am J Orthod Dentofac Orthop 1993;104(1):21-26.

16. Bishara SE, Vonwald L, Laffoon JF, Jakobsen JR. Effect of altering the type of enamel conditioner on the shear bond strength of a resin-reinforced glass ionomer adhesive. Am J Orthod Dentofac Orthop 2000;118(3):288-294.

17. Romano FL, Tavares SW, Nouer DF, Consani S, Borges de Araujo Magnani MB. Shear bond strength of metallic orthodontic brackets bonded to enamel prepared with SelfEtching Primer. Angle Orthod 2005;75(5):849-853.

18. Fernandez L, Canut JA. In vitro comparison of the retention capacity of new aesthetic brackets. Eur J Orthod 1999;21(1):71-77.

19. Zach L, Cohen G. Pulp response to externally applied heat. Oral Surg Oral Med Oral Pathol 1965;19(4):515-530.

20. Serebro L, Segal T, Nordenberg D, Gorfil C, Bar-Lev M. Examination of tooth pulp following laser beam irradiation. Lasers Surg Med 1987;7(3):236-239.

21. Goodis HE, Schein B, Stauffer P. Temperature changes measured in vivo at the dentinoenamel junction and pulpodentin junction during cavity preparation in the Macaca fascicularis monkey. J Endod 1988;14(7):336-339.

22. Obata A, Tsumura T, Niwa K, Ashizawa Y, Deguchi T, Ito M. Super pulse $\mathrm{CO}_{2}$ laser for bracket bonding and debonding. Eur J Orthod 1999;21(2):193-198. 